\title{
Using odour traps for population monitoring and dispersal analysis of the threatened saproxylic beetles Osmoderma eremita and Elater ferrugineus in central Italy
}

\author{
Agnese Zauli · Stefano Chiari · Erik Hedenström • \\ Glenn P. Svensson • Giuseppe M. Carpaneto
}

Received: 7 March 2014/ Accepted: 8 August 2014/Published online: 17 August 2014

(C) Springer International Publishing Switzerland 2014

\begin{abstract}
Pheromone-based monitoring could be a very efficient method to assess the conservation status of rare and elusive insect species, but there are still few studies for which pheromone traps have been used to obtain information on presence, abundance, phenology and movements of such insects. We performed a mark-recapture study of two threatened saproxylic beetles, Osmoderma eremita (Scarabaeidae) and its predator Elater ferrugineus (Elateridae), in two beech forests of central Italy using pheromone baited window traps and unbaited pitfall traps. Two lures were used: (1) the male-produced sex pheromone of $O$. eremita (racemic $\gamma$-decalactone) to attract females of both species, and (2) the female-produced sex pheromone of E. ferrugineus (7-methyloctyl (Z)-4-decenoate), to attract conspecific males. In total, 13 O. eremita and 1,247 E. ferrugineus individuals were trapped. For E. ferrugineus, males were detected earlier than females, and 7-methyloctyl (Z)-4-decenoate was much more efficient
\end{abstract}

A. Zauli $(\bowtie) \cdot$ G. M. Carpaneto

Department of Science, Roma Tre University,

Viale G. Marconi 446, 00146 Rome, RM, Italy

e-mail: agnese.zauli@uniroma3.it

G. M. Carpaneto

e-mail: giuseppe.carpaneto@uniroma3.it

\section{S. Chiari}

Department of Biology and Biotechnologies 'Charles Darwin', Sapienza University of Rome, Via A. Borelli 50, 00161 Rome, RM, Italy

e-mail: chiaristefano@gmail.com

\section{S. Chiari}

Corpo Forestale dello Stato, Centro Nazionale per lo Studio e la Conservazione della Biodiversità Forestale 'Bosco Fontana' di Verona (CNBFVR), Strada Mantova 29, 46045 Marmirolo, MN, Italy lure compared to racemic $\gamma$-decalactone in detecting its presence. The population size at the two sites were estimated to 520 and 1,369 individuals, respectively. Our model suggests a sampling effort of ten traps checked for 3 days being sufficient to detect the presence of E. ferrugineus at a given site. The distribution of dispersal distances for the predator was best described by the negative exponential function with $1 \%$ of the individuals dispersing farther than $1,600 \mathrm{~m}$ from their natal site. In contrast to studies on these beetles in Northern Europe, the activity pattern of the two beetle species was not influenced by variation in temperature during the season.

Keywords Conservation - Kairomone - Mark-recapture · Pheromone $\cdot$ Predator-Prey $\cdot$ Temperature 


\section{Introduction}

Semiochemicals are odorous molecules mediating both intraspecific and interspecific interactions (Gullan and Cranston 2010). The chemical ecology of insects, by the study of semiochemicals, started in 1950s with the identification of the silk moth sex pheromone (Butenandt et al. 1959). Since then, pheromones have largely been used with success for monitoring and control of pest insect in forestry, plantation and crop management (Witzgall et al. 2010). The advantages in the use of pheromones in monitoring of pest species are many, e.g. they are selective and very efficient at low population density (Witzgall et al. 2010). However there are still very few studies for which odour-baited traps have been used to study population parameters in rare and threatened insects. Ongoing research to implement semiochemical-based methods for conservation purposes includes some of the most charismatic and threatened European insects such as the moth Graellsia isabellae (Millar et al. 2010), and some beetles such as Lucanus cervus (Chapman et al. 2002; Harvey et al. 2011), Osmoderma eremita (Larsson et al. 2003; Svensson et al. 2003; Svensson and Larsson 2008), Osmoderma barnabita (Svensson et al. 2009), Elater ferrugineus (Svensson et al. 2004; Tolasch et al. 2007; Svensson and Larsson 2008; Musa et al. 2013; Andresson et al. 2014), Morimus asper (Chiari et al. 2013c) and Prionus sp. (Barbour et al. 2011). The use of attractive odour traps has been one of the most accredited approaches for monitoring presence and abundance of threatened beetles, especially those protected under the Habitat Directive.

All the above cited beetles belong to the functional group of the saproxylic, i.e. all the organisms that depend, during some parts of their life cycle, upon wounded or decaying woody material from living, weakened or dead trees (Speight 1989; Alexander 2008; Stockland et al. 2012). Saproxylic beetles are considered one of the most threatened insect groups in Europe mainly due to the modern forestry practices addressed to timber commercial use and dead wood harvesting, that deplete the amount of this resource and negatively affect the habitat quality for these organisms (Grove 2002; Davies et al. 2008; Thomas et al. 2009). Moreover, most of the saproxylic beetles are difficult to detect because they may occur at small population sizes and/or live hidden in tree microhabitats like wood crevices or tree holes. In this context, an efficient odour lure can be very useful for detecting a species, assessing its population size, studying its dispersal capacity and flight phenology, as well as mapping its geographical distribution through large-scale surveys. Furthermore, as the sampling effort with odour traps could be standardized, it is possible to describe variations in the population parameters of a species in space and time.

The systematic review of Brouwers and Newton (2009) revealed that only a limited number of studies provided measures of movement rate for woodland invertebrates. No studies have been conducted on dispersal ability of forest click beetles but a few studies have estimated dispersal distances in pest click beetles (Yamamura et al. 2003; Blackshaw and Vernon 2006; Arakaki et al. 2008; Schallhart et al. 2009). Detailed information on the dispersal ability (i.e. dispersal rate and range) is fundamental for assessing the extinction risk of local populations of threatened species, especially in saproxylic beetles, of which many species are today threatened due to habitat loss and fragmentation (Ranius 2006).

Only a few studies on IUCN listed saproxylic beetles, by means of mark-recapture, have been carried out in the Mediterranean region (López-Pantoja et al. 2008; 2011; Torres-Vila et al. 2012; Chiari et al. 2013a), and none of them was focused on the predator-prey system represented by E. ferrugineus (Coleoptera, Elateridae) and O. eremita (Coleoptera, Scarabaeidae), which has been extensively studied in northern Europe (Svensson et al. 2004; Larsson and Svensson 2009, 2011).

The larvae of E. ferrugineus, live in hollow trees and feed on the immature stages of other saproxylic beetles, mostly those of flower chafers, including O. eremita (Iablokoff 1943; Platia 1994; Schaffrath 2003b; Tolasch et al. 2007). Svensson et al. (2004) showed that adult females of E. ferrugineus are attracted by the male-produced sex pheromone $(R)-(+)-\gamma-$ decalactone, of $O$. eremita, using this compound as a kairomone in order to locate suitable tree cavities in which to lay eggs. On the contrary, males of E. ferrugineus are strongly attracted to the sex pheromone 7-methyloctyl $(Z)$-4-decenoate emitted by conspecific females (Tolasch et al. 2007; Svensson et al. 2012). Both E. ferrugineus and O. eremita are listed as Near Threatened (NT) in the IUCN European Red List of Saproxylic Beetles (Nieto and Alexander 2010), and $O$. eremita is also listed in the EU Habitat Directive as a priority species of community interest (Anonymous 1992).

The goal of this work was to use different trapping methods to analyse some aspects of the population ecology of $E$. ferrugineus and $O$. eremita at two locations in the Mediterranean region with the following aims: (a) testing the efficacy of the traps baited with the racemic $\gamma$-decalactone and 7-methyloctyl (Z)-4-decenoate in capturing adults of these two species; (b) estimating population size of the two species; (c) obtaining estimates of dispersal rates and distances; (d) obtaining phenological data and investigating the adult activity in relation to the variation in seasonal climatic conditions.

\section{Materials and methods}

\section{Study areas}

The study was carried out in central Italy (Latium region), in two Sites of Community Importance (SCI): "Boschi mesofili 
di Allumiere" (hereafter "Allumiere") (IT6030003) $\left(42^{\circ} 09^{\prime} \mathrm{N} 11^{\circ} 54^{\prime} \mathrm{E}, 520-630 \mathrm{~m}\right.$ a.s.l.) and "Monte Fogliano e Monte Venere" (hereafter "Monte Venere") (IT6010023) $\left(42^{\circ} 21^{\prime} \mathrm{N} 12^{\circ} 11^{\prime} \mathrm{E}, 580-840 \mathrm{~m}\right.$ a.s.1.).

These highly natural forests of beech (Fagus sylvatica) represent two secondary old-growth stands of the primeval forests that covered part of the Latium region during the cool and humid phases of Pleistocene (Magri 1998; 2008; Piovesan et al. 2011; Ziaco et al. 2012). These relatively small stands (45 ha Allumiere and 170 ha Monte Venere) occur at lower elevation in respect to the large mountain beech forests still widely spread along the Apenninic range between 900 and 2,000 $\mathrm{m}$ a.s.l.

\section{Sampling design}

A mark-recapture study was conducted between 10th June and 25th July 2012, within an area of two hectares in each forest. Two trap types were used: Pitfall Traps (PT) and Black Cross Window Traps (BCWT). PT were empty jars, without an odour bait, placed inside tree hollows, with the opening (diameter of $7 \mathrm{~cm}$ ) at the level of the wood mould surface (Ranius 2001). In total 23 PT (17 in Allumiere and six in Monte Venere) were set in all the accessible tree cavities occurring within the selected areas. BCWT, the same as used by Svensson and Larsson (2008) and Chiari et al. (2013a), were suspended from tree branches at 2-4 m height. For each replicate two traps were baited respectively with: (a) $1,200 \mu \mathrm{l}$ of neat racemic mixture of $\gamma$-decalactone (Sigma-Aldrich, USA) as pheromone to attract $O$. eremita (both sexes) and as kairomone lure to attract $E$. ferrugineus (mainly females); (b) $2 \mu \mathrm{l}$ of neat 7-methyloctyl (Z)-4-decenoate as pheromone to attract E. ferrugineus males (Svensson et al. 2012). The racemic $\gamma$-decalactone was loaded in a $2 \mathrm{ml}$ plastic Eppendorf tube with cut strings of cotton as wicks. The vials were replaced at every fourth trap checking. The 7-methyloctyl (Z)-4decenoate was loaded in a PCR tube pierced with an insect pin size 3 to release the pheromone (Tolasch et al. 2007; Svensson et al. 2012). In this case, the same vials were used throughout the whole trapping experiment. BCWT within the same replicate were placed at least $10 \mathrm{~m}$ apart. Each replicate was separated by at least $100 \mathrm{~m}$ to increase spatial independence. The number of BCWT replicates was 27 for each study area. In five cases (three in Allumiere and two in Monte Venere) the PT was set in the same tree as the BCWT. Traps were checked every second day and, to avoid position effects, the relative positions of BCWT within each replicate were changed four times during the study period. To avoid influencing the survival probability of captured adults at the end of the season, traps were removed when the number of capture events showed a clear decline. In addition to trap captures, all beetles encountered outside traps during trap checking (Visual Encounter Surveys, VES) were captured as well (cfr. Chiari et al. 2013a).

At first capture, every beetle was sexed and marked with a unique code: $O$. eremita with fine pits produced by a small drill (Dremel Lithium Cordless 8000JE) on both elytra (Ranius 2001; Chiari et al. 2013a), and E. ferrugineus with a fine point permanent marker pen (Uni Paint Marker PX-21) on the ventral sclerites. Beetles were normally released on the trunk of the trap tree, even if most the individuals of E. ferrugineus flew away from the operator's hand after being marked.

\section{Data analysis}

\section{Population estimates}

Population size estimates for each species were generated with male and female data pooled together and repeated captures in the same sampling occasion were counted only once.

The daily population size was estimated by the JollySeber method for open populations, as implemented in Simply Tagging (vers. 2.0.1.27; Pisces Conservation Ltd, 2009). In order to allow comparison with other studies, the overall population size was estimated using Craig's model for closed populations (Craig 1953). The coefficient of variation (C.V.) was calculated as the ratio between the standard deviation and mean population size. We refer to a closed population as one in which the total number of individuals is not changing through births, deaths, immigration or emigration, and an open population as one that is changing during the course of a study because of any combination the parameters previously cited (Amstrup et al. 2005).

\section{Capture probability and survey effort allocation}

Occupancy models for multiple detection methods were used to obtain method specific detection probabilities $\left(\widehat{p}_{T}\right)$ and to estimate occupancy at large $(\psi)$ and small $(\theta)$ spatial scales (Nichols et al. 2008). The $\psi$ parameter estimates the probability that a randomly selected site of the study area is occupied, whereas the $\theta$ parameter estimates the probability that the species occurs at the local sample station. Detection probability was modelled as constant over time and detection methods $(p)$, as time-independent but different among methods $\left(p^{s}\right)$, as time-dependent but constant among methods $\left(p_{t}\right)$, or with method as an additive effect with time $\left(p_{s+t}\right)$. Small-scale occupancy was modelled as either time-independent $(\theta)$ or time-dependent $\left(\theta_{t}\right)$. Analyses were carried out using the program PRESENCE (Hines and MacKenzie 2004) with single-season multi- 
method models that were ranked according to their values of AICc (Akaike Information Criterion corrected for small sample size) or QAIC (Quasi Akaike Information Criterion), with models having more support (low AICc or QAIC value) being highly ranked (Burnham and Anderson 2002).

To evaluate the survey effort necessary to achieve a standard error of 0.05 for the occupancy estimator $\widehat{\psi}$, given the calculated $\psi$ and $p$, the value of $s$ (number of sites to investigate, in our case the number of traps) and $K$ (number of surveys) were evaluated according to the equation of MacKenzie and Royle (2005):

$\operatorname{var}(\widehat{\psi})=\frac{\psi}{s}\left[(1-\psi)+\frac{\left(1-p^{*}\right)}{p^{*}-K p\left(1-p^{*}\right)^{K-1}}\right]$

where $p^{*}=1-(1-p)^{K}$ is the probability of detecting the species at least once during $K$ surveys of an occupied site.

The purpose of this analysis is to determine what values of $s$ and $K$ are to be used to most efficiently achieve the desired level of precision for the value of $\widehat{\psi}$ using the different trap types. The values of $\psi$ and $p$ in the equation were the ones resulted from the best model previously selected.

\section{Dispersal distances and patterns}

Straight distances between the traps that captured individual beetles were summed to obtain a conservative measure of the overall movements for each beetle captured more than once. Analyses were carried out by pooling distance values obtained from the two forests. The Mann-Whitney U-test was used to test differences between distances covered by males and females for each species. The distributions of dispersal distances were fitted to a negative exponential function, $\mathrm{P}=\mathrm{e}^{(-D / k)}$, and a power function, $\mathrm{P}=a D^{-n}$, where $\mathrm{P}$ is the probability that an individual covers the distance $D$ or farther, and $a, n$, and $k$ are constants (Ranius 2006; Drag et al. 2011; Svensson et al. 2011; Chiari et al. 2013b). Analyses were performed with STATISTICA 7.0 (StatSoft Inc., 2004), using a significance level of 0.05 to reject the null hypothesis.

\section{The influence of temperature on beetle activity}

To assess the influence of temperature on E. ferrugineus individual activity, the daily maximum temperature was correlated to the number of catches registered for each sampling occasion. For each species, activity data of males and females were analyzed separately, but pooled for the two study areas. For Allumiere, data on daily temperatures were obtained by the meteorological station in Allumiere municipality operated by the public regional hydrographic office (Ufficio Idrografico 2013). Whereas, for Monte Venere, data were obtained from the meteorological station (ILAZIOCA3) in Caprarola municipality, about $3 \mathrm{~km}$ from the study area (Wunderground 2013).

\section{Results}

\section{Capture data}

No beetles were captured in PT, and all captures thus refer to odour-baited BCWT. In addition, a total of nine males $E$. ferrugineus were found by visual encounter survey (VES) (three in Allumiere and six in Monte Venere). In total, 13 individuals of $O$. eremita were captured (four in Allumiere, nine in Monte Venere), with a total of 22 capture events (four in Allumiere, eighteen in Monte Venere) (Table 1). In contrast, 1,247 individuals of E. ferrugineus were captured (374 in Allumiere, 873 in Monte Venere), with a total of 2,151 capture events (687 in Allumiere, 1,464 in Monte Venere) (Table 1). The recapture rate of E. ferrugineus males was $55 \%$ in Allumiere and $50 \%$ in Monte Venere, whereas the recapture rate of females was $10 \%$ in both study areas. The number of individuals captured was significantly higher for males than for females in both study areas (Allumiere, $\chi^{2}=443.63, d f=1, p<0.001$; Monte Venere, $\left.\chi^{2}=419.75, d f=1, p<0.001\right)$ and the same pattern was shown for the number of recapture events (Allumiere, $\chi^{2}=7.80, d f=1, p<0.005$; Monte Venere, $\left.\chi^{2}=39.35, d f=1, p<0.001\right)$.

The first capture of $O$. eremita was observed on 3rd July in Allumiere and on 24th June in Monte Venere; whereas, the last capture was observed on 20th July in Allumiere and on 23rd July in Monte Venere. For E. ferrugineus, the first male was captured on 15th June in Allumiere and on 19th June in Monte Venere, while the first female was found on 30th June in Allumiere and on 29th June in Monte Venere. The last capture for both sexes was performed on 24th July in Allumiere, while in Monte Venere the last capture of a male was performed on 25th July and of a female on 23rd July.

Of all $O$. eremita captured more than twice, only one female in Monte Venere was observed to come back to a trap of a previous capture. Of all E. ferrugineus captured more than twice, $5 \%$ in Allumiere and $8 \%$ in Monte Venere were observed to come back to a trap of a previous capture. No O. eremita and $7 \%$ of E. ferrugineus were captured more than once during the same sampling occasion.

No $O$. eremita was injured by the trapping procedure, while $20 \%$ of $E$. ferrugineus individuals were found dead in the traps. Of these, $36 \%$ were found dead at first 
Table 1 Summary of the mark-recapture data obtained during the study of Osmoderma eremita and Elater ferrugineus in the two beech forests, Allumiere and Monte Venere, of Central Italy with different capture methods

\begin{tabular}{|c|c|c|c|c|c|}
\hline \multirow[t]{2}{*}{ Method } & \multirow[t]{2}{*}{ Species } & \multicolumn{2}{|l|}{ Allumiere } & \multicolumn{2}{|l|}{ Monte Venere } \\
\hline & & Individuals $(\hat{\jmath} / P)$ & Capture events $(\hat{\jmath} / \stackrel{+}{)})$ & Individuals $(\hat{\delta} / P)$ & Capture events $(\hat{\partial} /$ o $)$ \\
\hline \multirow[t]{2}{*}{ BCWT Elater } & O. eremita & $0 / 0$ & $0 / 0$ & $0 / 0$ & $0 / 0$ \\
\hline & E. ferrugineus & $352 / 2^{\mathrm{a}}$ & $657 / 2$ & $734 / 2^{\mathrm{b}}$ & $1,295 / 2$ \\
\hline \multirow[t]{2}{*}{ BCWT Osmoderma } & O. eremita & $1 / 3$ & $1 / 3$ & $0 / 9$ & $0 / 18$ \\
\hline & E. ferrugineus & $5^{\mathrm{c}, \mathrm{d}} / 19^{\mathrm{e}}$ & $5^{\mathrm{c}} / 20$ & $13^{\mathrm{f}, \mathrm{g}} / 134^{\mathrm{h}}$ & $13^{\mathrm{f}} / 148$ \\
\hline \multirow[t]{2}{*}{ VES } & O. eremita & $0 / 0$ & $0 / 0$ & $0 / 0$ & $0 / 0$ \\
\hline & E. ferrugineus & $3^{\mathrm{i}} / 0$ & $3 / 0$ & $6^{\mathrm{i} / 0}$ & $6 / 0$ \\
\hline \multirow[t]{2}{*}{ PT } & O. eremita & $0 / 0$ & $0 / 0$ & $0 / 0$ & $0 / 0$ \\
\hline & E. ferrugineus & $0 / 0$ & $0 / 0$ & $0 / 0$ & $0 / 0$ \\
\hline
\end{tabular}

BCWT Elater = black cross window trap baited with 7-methyloctyl (Z)-4-decenoate; BCWT Osmoderma = black cross window trap baited with racemic $\gamma$-decalactone; VES = visual encounter survey; PT = unbaited pitfall trap

${ }^{a}$ Individuals of which 1 recaptured with BCWT Osmoderma

b All individuals previously captured or then recaptured with BCWT Osmoderma

c Individuals/captures of which 2 found/performed in traps with at least 1 E. ferrugineus female

${ }^{\mathrm{d}}$ Individuals of which 3 previously captured or then recaptured with BCWT Elater

${ }^{\mathrm{e}}$ Individuals of which 1 recaptured with BCWT Elater

${ }^{\mathrm{f}}$ Individuals/captures of which 11 found/performed in traps with at least 1 E. ferrugineus female

$\mathrm{g}$ Individuals of which 8 previously captured or then recaptured with BCWT Elater

h Individuals of which 2 recaptured with BCWT Elater

i All individuals previously captured or then recaptured with BCWT Elater

capture, and $64 \%$ at a subsequent capture. The majority of these captures took place at the end of the field season.

Population estimates

Due to the small number of $O$. eremita captures in both study areas, it was not possible to obtain any population estimate for this species.

The daily estimates of population size of E. ferrugineus based on the Jolly-Seber method are shown in Fig. 1a, b. Based on Craig's method, the total population size $( \pm 95 \%$ confidence interval) was $520 \pm 41(\mathrm{C} . \mathrm{V} .=0.08)$ in $\mathrm{Al}-$ lumiere and 1,369 \pm 86 (C.V. $=0.06)$ in Monte Venere.

Capture probability and survey effort allocation

All O. eremita individuals were captured in BCWT baited with racemic $\gamma$-decalactone, but due to the low number of captures it was not possible to build occupancy models for this species. All E. ferrugineus were captured by BCWT or VES (Table 1). The median number of captures per trap was 20 (range 5-84) in Allumiere and 53 (range 18-92) in Monte Venere.

In both study areas, the estimated large-scale probability of occupancy for E. ferrugineus was very high (Allumiere $\psi=1, \mathrm{SE}=0$; Monte Venere $\psi=1, \mathrm{SE}=0$ ). Model selection statistics provided strong evidence that occupancy probabilities, in both study areas, were influenced by sampling method $(s)$ and time $(t)$ (Table 2). The BCWT baited with 7-methyloctyl (Z)-4-decenoate performed much better than those baited with racemic $\gamma$-decalactone in detecting the presence of E. ferrugineus, showing a model average of $\widehat{p}=0.68(\mathrm{SE}=0.10)$ in Allumiere and $\widehat{p}=$ 0.89 ( $\mathrm{SE}=0.05)$ in Monte Venere. In contrast, the probability of detecting the presence of E. ferrugineus by BCWT baited with racemic $\gamma$-decalactone was $\widehat{p}=0.01$ $(\mathrm{SE}=0.01)$ in Allumiere and $\widehat{p}=0.11(\mathrm{SE}=0.05)$ in Monte Venere (Table 3).

To achieve a SE of 0.05 for the estimate of the parameter $\psi$, using the values obtained for $\widehat{p}$, with the BCWT baited with 7-methyloctyl (Z)-4-decenoate, it is sufficient to use ten traps which are checked three times during the experimental period in both study sites (Allumiere SE $\psi=0.034$, Monte Venere SE $\psi=0.020$ ). In contrast, to achieve the same SE for $\psi$ using traps baited with racemic $\gamma$-decalactone, the field effort should be at least 250 traps for 130 surveys in Allumiere (SE $\psi=0.054$ ) and 20 traps for 30 surveys in Monte Venere (SE $\psi=0.042$ ). As the best fitting model for both study areas is the one with $p$ changing with time, the $p_{t}$ values for each sampling occasion were considered in the analysis of the sampling effort and the variation of the SE for 

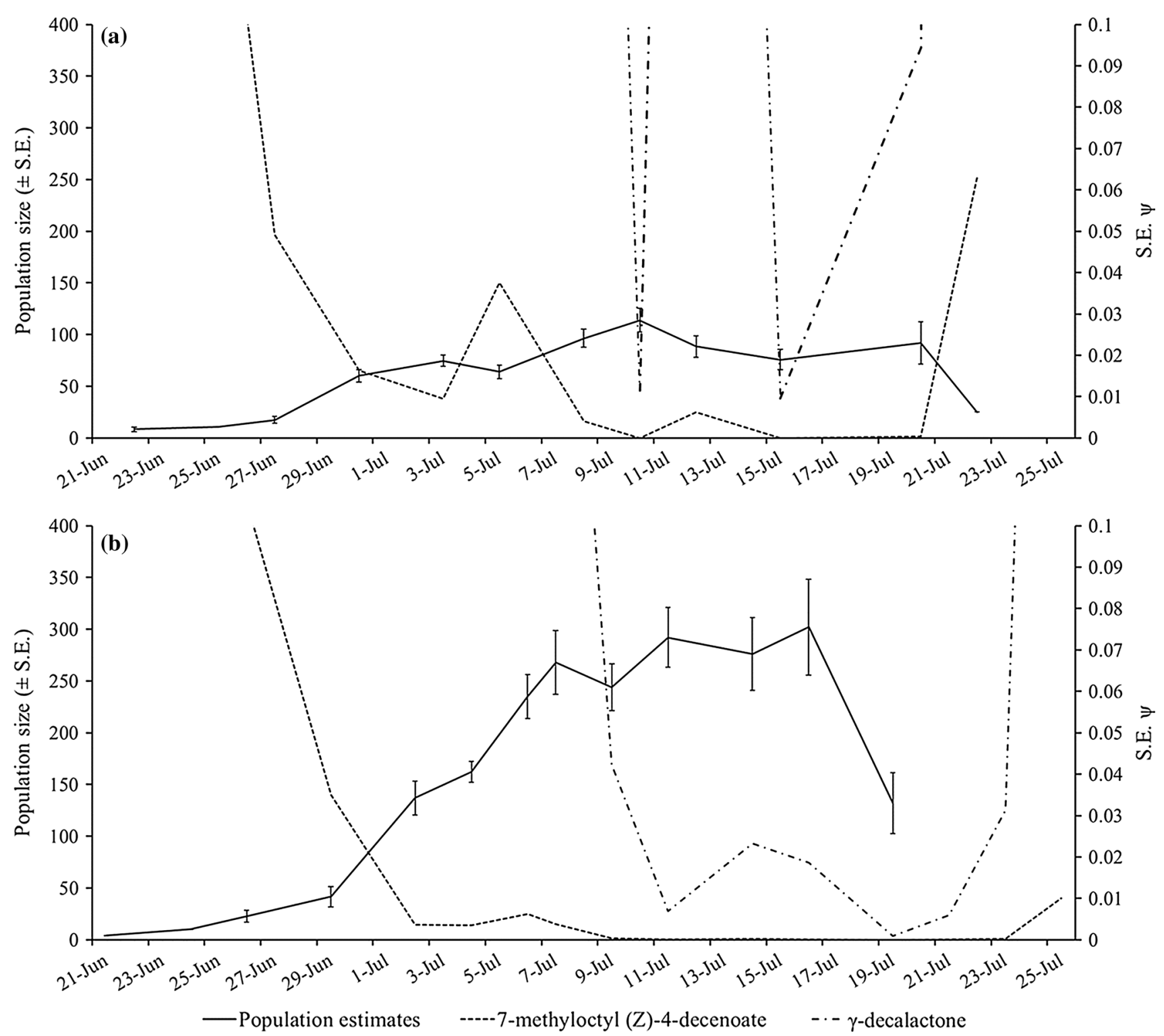

Fig. 1 Elater ferrugineus daily estimates of population size and variation of the standard error of the occupancy estimator $\widehat{\psi}$ for black cross window traps baited with 7-methyloctyl (Z)-4-decenoate and $\gamma$-decalactone during the study period in Allumiere (a) and Monte Venere (b). The population estimates are obtained from the markrecapture data with males and females data pooled using the Jolly-Seber method in Simply Tagging. The variation of SE of $\widehat{\psi}$ is

$\psi$ is reported in Fig. 1a, b. In this case, the SE variation during the sampling period was obtained by hypothesizing to set ten BCWT baited with 7-methyloctyl (Z)-4decenoate for four days for both study areas. Instead, to obtain the S.E: variation using BCWT baited with racemic $\gamma$-decalactone was hypothesize to set 40 traps for 20 days in Allumiere (Fig. 1a), where the population is smaller, and 20 BCWT baited with racemic $\gamma$-decalactone for ten days in Monte Venere (Fig. 1b), where the population is larger. evaluated for the black cross window traps baited with 7-methyloctyl (Z)-4-decenoate hypothesizing to use ten traps checked four times for both the study areas. The variation of SE of $\widehat{\psi}$ is evaluated for the black cross window traps baited with $\gamma$-decalactone hypothesizing to use 40 traps for checked 20 times in Allumiere and 20 traps checked ten times in Monte Venere

\section{Dispersal distances and patterns}

Spatial displacements of $O$. eremita were recorded only in Monte Venere, where four females out of nine moved from the site of the first capture to another trap, covering a median distance of $353 \mathrm{~m}$ (range 201-523 m).

Spatial displacements of E. ferrugineus in Allumiere were recorded for 149 out of 194 recaptured males (77\% of the recaptured males) and two females (100\% of the recaptured females). Males moved from the site of first 
Table 2 Summary of the model selection statistics for the models from the data of Elater ferrugineus in the two beech forests of Allumiere $(a)$ and Monte Venere $(b)$ in Central Italy

\begin{tabular}{lrcrl}
\hline Model & $K$ & $-2 \log (L)$ & \multicolumn{1}{c}{$\Delta$ AIC $c$} & \multicolumn{1}{l}{$w$} \\
\hline (a) Allumiere & & & & \\
$\psi, \theta, p_{s+t}$ & 20 & 595.84 & 0.00 & 0.99 \\
$\psi, \theta_{t}, p^{s}$ & 20 & 604.40 & 8.56 & 0.01 \\
$\psi, \theta, p^{s}$ & 4 & 763.18 & 135.34 & 0.00 \\
$\psi, \theta, p$ & 3 & $1,092.34$ & 462.50 & 0.00 \\
\hline Model & $K$ & $-2 \log (L)$ & \multicolumn{1}{c}{$\Delta$ QAIC } & \multirow{2}{*}{$w$} \\
\hline
\end{tabular}

(b) Monte Venere

$\begin{array}{lrrrr}\psi, \theta, p_{s+t} & 20 & 608.05 & 0.00 & 1.00 \\ \psi, \theta_{t}, p^{s} & 20 & 679.11 & 25.37 & 0.00 \\ \psi, \theta_{t}, p_{s+t} & 36 & 592.44 & 26.43 & 0.00 \\ \psi, \theta, p^{s} & 4 & 935.89 & 85.03 & 0.00 \\ \psi, \theta, p_{t} & 19 & 939.82 & 116.43 & 0.00 \\ \psi, \theta_{t}, p & 19 & 1,000.13 & 137.96 & 0.00 \\ \psi, \theta, p & 3 & 1,177.12 & 169.13 & 0.00\end{array}$

$K$ represents the number of parameters in the model and $-2 \log (L)$ is twice the negative log-likelihood value. Small sample Akaike Information Criterion (AICc) and Quasi Akaike Information Criterion (QAIC) were calculated for the models relative to Allumiere and Monte Venere, respectively. Relative AIC $c$ and QAIC values and Akaike weight, $w$, are reported. $\triangle \mathrm{AIC} c$ and $\triangle \mathrm{QAIC}$ represents the difference in $\mathrm{AIC} c$ and QAIC values relative to the top model (Burnham \& Anderson 2002). Detection probabilities may vary among methods $(s)$ or sampling occasions $(t)$

Table 3 Elater ferrugineus detection probability estimates $(\widehat{p})$ and associated standard error (in parenthesis) are given for multi-method models using the black cross window traps baited with 7-methyloctyl $(Z)$-4-decenoate $(E f)$ and racemic $\gamma$-decalactone $(O e)$ in Allumiere (a) and Monte Venere $(b)(\mathrm{w}=$ Akaike's weight for each model)

\begin{tabular}{llll}
\hline Model & $w$ & $\widehat{p}_{E f}(\mathrm{SE})$ & $\hat{p}_{O e}(\mathrm{SE})$ \\
\hline
\end{tabular}
(a) Allumiere

$\begin{array}{llll}\psi, \theta, p_{s+t} & 0.99 & 0.68^{\mathrm{a}}(0.10) & 0.01^{\mathrm{a}}(0.01) \\ \psi, \theta_{t}, p^{s} & 0.01 & 1.00(00) & 0.07(0.02) \\ \psi, \theta, p^{s} & 0.00 & 1.00(00) & 0.07(0.02) \\ \psi, \theta, p & 0.00 & 0.28(0.01) & 0.28(0.01)\end{array}$

(b) Monte Venere

$\begin{array}{llll}\psi, \theta, p_{s+t} & 1.00 & 0.89^{\mathrm{a}}(0.05) & 0.21^{\mathrm{a}}(0.06)\end{array}$

${ }^{a}$ Parameter estimate reported is the median value among the 17 detection probability estimates for each detection method

capture covering a median distance of $214 \mathrm{~m}$ (range 10-1,561 m), whereas the two females moved 90 and $299 \mathrm{~m}$, respectively. In Monte Venere, 336 out of 366 males (92\% of the recaptured males) and twelve out of 14 females ( $86 \%$ of the recaptured females) moved from the site of first capture covering a median distance of $276 \mathrm{~m}$ (range 10-1,507 $\mathrm{m}$ ) and 317 (range 123-895 m),

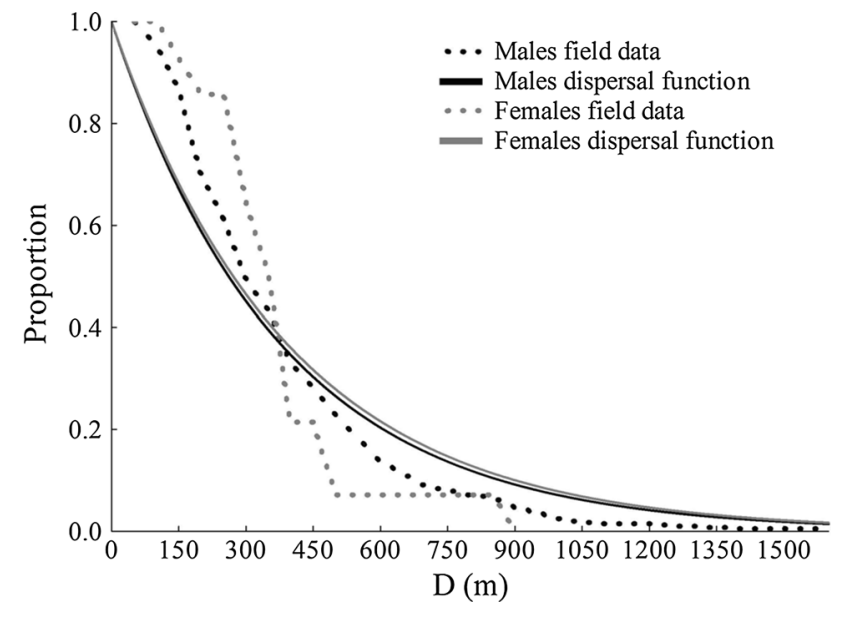

Fig. 2 Cumulative proportion of dispersing Elater ferrugineus males and females. Field data from the mark-recapture study combined for the two study areas (Allumiere and Monte Venere) $\left(\mathrm{N}_{\text {males }}=485, \mathrm{~N}_{\text {females }}=14\right.$ ) are compared with the exponential functions $\mathrm{P}=\mathrm{e}^{(-D / 7.54)}$ for males and $\mathrm{P}=\mathrm{e}^{(-D / 7.83)}$ for females, where $\mathrm{P}$ is the probability that a dispersing individual exceeds the distance $\mathrm{D}(\mathrm{m})$

respectively. The median dispersal distance did not differ significantly between sexes (Mann-Whitney U-test, $\mathrm{U}=3,030, \mathrm{Z}=0.69, p=0.49$ ). Field data on dispersal distances show that, for both sexes, the negative exponential function (Pearson Correlation Coefficient: males $r_{p}=0.973$, females $\left.r_{p}=0.895\right)$ fits better than the power function (males $r_{p}=0.893$, females $r_{p}=0.817$ ) in describing the distribution of dispersal distances (Fig. 2). For both sexes, the first model predicted that about $1 \%$ of the individuals will disperse farther than $1,600 \mathrm{~m}$ from their natal site; about $51 \%$ will disperse farther than $250 \mathrm{~m}$, and about $77 \%$ will move farther than $100 \mathrm{~m}$.

The influence of temperature on beetle activity

For E. ferrugineus, the number of catches showed no correlation with the daily maximum temperature for any of the sexes (Fig. 3). During the study period, the temperature fluctuated from about $11^{\circ}$ to $33^{\circ} \mathrm{C}$.

\section{Discussion}

We used pheromone-baited traps to obtain estimates of population size, flight phenology, dispersal rates and distances, as well as the effect of temperature on the flight activity in two saproxylic beetles, $O$. eremita and E. ferrugineus, at two sites in Italy. Similar analyses have been performed on Swedish populations of these species. The current study and previous Italian studies on $O$. eremita by Chiari et al. $(2012,2013 \mathrm{a}, \mathrm{b})$, thus enables comparisons of population parameters in the southern and 
Fig. 3 The relationship between catch rates of E. ferrugineus and temperature during the sampling season. Catch rate is an indicator of activity and it is not correlated with the daily maximum temperatures registered during the study period

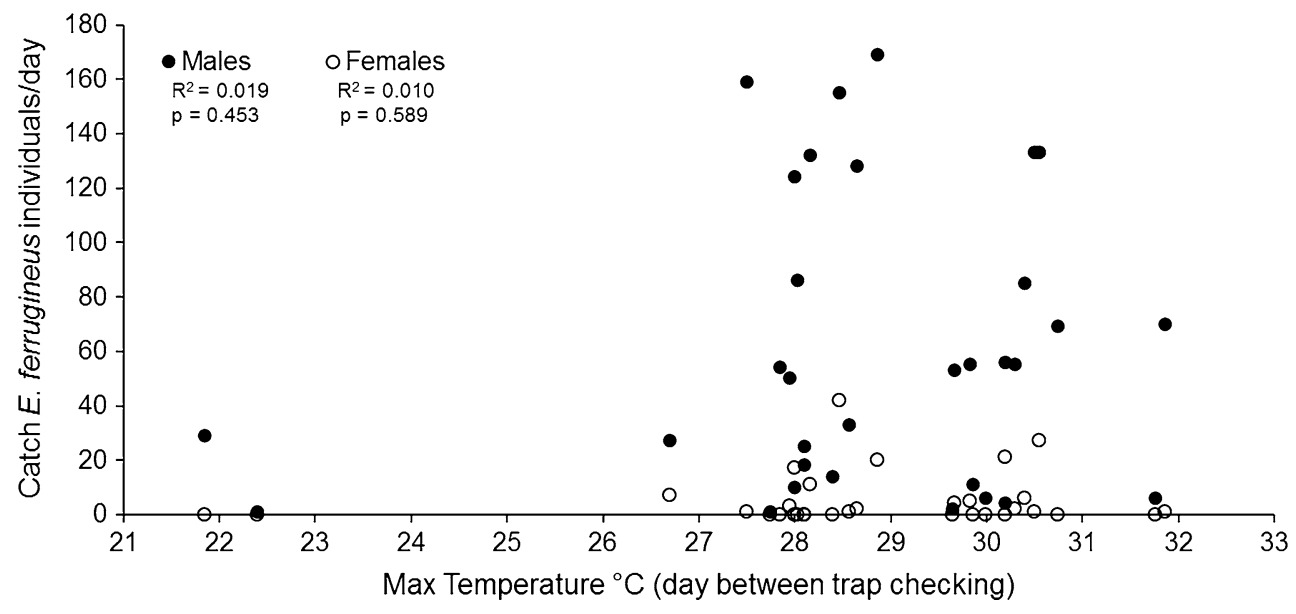

northern parts of the distribution of these beetles. The differences found between northern (Sweden) and southern (Italy) populations of these beetles mainly concern three aspects: (1) the dispersal rates and distances, which are higher in the south than in the north, probably due to the different distribution of suitable habitat in the two regions (Hedin et al. 2008; Svensson et al. 2011; Chiari et al. 2013b); (2) the hollow trees selected for the oviposition that have a sunny exposure in the north while are not influenced by exposure at south (Ranius and Nilsson 1997 vs. Chiari et al. 2012); (3) the flight activity, related to temperature variations during the season at north, while not depending on the same parameter at south, at least for E. ferrugineus (Larsson and Svensson 2011 vs. present study).

Capture data and population estimates

A much higher number of captures of the predator $E$. ferrugineus was observed compared to the prey $O$. eremita. Even considering only E. ferrugineus captures in traps baited with racemic $\gamma$-decalactone, the predator/prey ratio was very high (Allumiere 26/4, Monte Venere 161/18). This is in contrast to the results of the studies on Swedish populations of these beetles, where this ratio was less than one (Larsson and Svensson 2011). Even higher would be the predator/prey ratio if we consider the number of individuals captured with the specific pheromone (Allumiere 659/4, Monte Venere 1307/18). This can be explained with the lower consistency of the $O$. eremita populations in the study areas than in Sweden (cf. Ranius 2001) and suggests that in the south E. ferrugineus is more generalist than expected in prey selection. Due to the rareness of $O$. eremita at the study sites, we may suppose that $E$. ferrugineus in these forests can also feed on larvae of other scarab beetles as Cetonia aurata, Potosia cuprea, Cetonischema aeruginosa, Netocia morio, Gnorimus variabilis, Oryctes nasicornis and/or also on other larvae, e.g. those of darkling beetles. In captivity, the larvae of E. ferrugineus were observed to feed on earthworms (AZ personal observation) and therefore we cannot exclude that also other invertebrates are included in their diet.

In this study, the captures of $O$. eremita are much less numerous than those performed in the studies conducted in northern Europe using the same method (Ranius 2001; Svensson et al. 2004; Larsson and Svensson 2011) and in other areas of central Italy (Chiari et al. 2013a), suggesting that these are small populations exposed to local extinction risk (Boyce 1992). In the study of Larsson and Svensson (2011) with a similar number of traps $(\mathrm{N}=24-28$ during different years), baited with $\gamma$-decalactone, between 6 and 30 E. ferrugineus captures were observed, probably all females. In the present study, the greatest number of captures (161) was observed in Monte Venere, indicating a larger consistency of this Italian population respect to the Swedish ones. However, other factors such as temperature may influence the catchability of E. ferrugineus (Larsson and Svensson 2011) making it difficult to compare the absolute size of populations in different parts of its distribution range.

The use of traps baited with 7-methyloctyl (Z)-4-decenoate allowed the capture of a large number of $E$. ferrugineus. The identification of the sex pheromone of this species was based on analyses of German and Swedish populations, and the high catches at the Italian sites show that this compound can be used to survey populations throughout the distribution range of the species. In the study of a Swedish population by Svensson et al. (2012), the recapture rate of males using traps baited with 7-methyloctyl (Z)-4-decenoate was 54-63\%, which is similar to the 50-55\% recaptures found in the present study. The population estimates revealed that the Monte Venere population was three times large as the Allumiere population and this fact is probably due to the greater structural continuity in the former forest than in the latter 
one. In fact, the beech forest of Monte Venere is wider and connected with other deciduous woodlands. This favours a larger population size and facilitates connectivity with other populations.

During the season, E. ferrugineus males were detected earlier than females in both study areas, suggesting that they emerged in advance, or simply became active as early as two weeks before than females. Protandry is a common feature of species with a restricted breeding season and a multitude of adaptive hypotheses for this mechanism have been proposed during the last 50 years (see Morbey and Ydenberg 2001 for a review). However sex pheromone or kairomone-guided behaviour of insects can be modulated, among other factors, by the mating status of the individuals (Anton et al. 2007). Therefore an alternative explanation for the different timing of catches between sexes could be that females may not respond behaviourally to the kairomonal cue, or will not disperse from their natal tree, until they are mated, which will result in female captures in traps baited with racemic $\gamma$-decalactone occurring later in the season compared to male captures in traps baited with 7-methyloctyl (Z)-4-decenoate. In a Swedish study on O. eremita, a high proportion $(79 \%)$ of the females captured in pheromone-baited traps were mated (Svensson et al. 2011), which partly supports the hypothesis that they mainly disperse after mating.

\section{Capture probability and survey effort allocation}

Pitfall traps have been successfully used to monitor populations of $O$. eremita, both in Sweden and Italy (Ranius 2001; Chiari et al. 2013a). In another Swedish study (Larsson and Svensson 2009) also E. ferrugineus was caught in PT, although in low numbers. On the contrary, in the present study none of the two target species was captured with this trap type. The main reason for this difference in PT catches between studies in Sweden and Italy could be that the Swedish sites included larger trees with a higher amount of wood mould in their hollows, suitable to sustain larger population of the beetles. The small volume of wood mould in the trees of the Italian sites could have made less efficient the PT method.

Observations of E. ferrugineus by VES were very rare. In total, only nine males were detected by VES versus the 1,247 captured by BCWT. Moreover, these nine individuals were found in flight during the trap checking, when BCWT had been lowered at eye level and most probably these males were attracted by 7-methyloctyl (Z)-4-decenoate. In this way the beetles attracted by the pheromone could be caught by hand. There is no information about the height at which E. ferrugineus flies, but our pheromone traps placed at a few meters height were efficient in capturing beetles. All the individuals observed to fly soon after the release reached immediately the height of about 10 meters and then took refuge into the tree canopy. Probably, this propensity to fly at high altitude may explain the rareness of direct field observation of this species.

Most $(72 \%)$ E. ferrugineus males captured by BCWT baited with racemic $\gamma$-decalactone were found together with at least one female. In one trap it was also possible to observe a pair of mating individuals. This result can be explained in two ways: (1) racemic $\gamma$-decalactone is used by $E$. ferrugineus males as an indirect cue to find conspecific females (Svensson et al. 2004); (2) the E. ferrugineus females, once captured in the racemic $\gamma$-decalactone baited traps, can continue to emit pheromone and attract males to that trap. According to Svensson et al. $(2004 ; 2009 ; 2011)$ the $(R)-(+)$ $\gamma$-decalactone could be a habitat cue or a territorial signal, emitted by males and exploited by the females of $O$. eremita to track the optimal trees for egg-laying, rather than a classical sexual pheromone. On the contrary, 7-methyloctyl (Z)4-decenoate is a true sexual pheromone that allows the males of E. ferrugineus to trace conspecific females.

Similar to the results obtained for Swedish population of E. ferrugineus (Svensson et al. 2012), the BCWT baited with 7-methyloctyl (Z)-4-decenoate performed much better than those baited with racemic $\gamma$-decalactone, and the probability of detecting the species ranged from $64 \%$ to $75 \%$ in Allumiere and Monte Venere, respectively. This indicating that the own pheromone is the optimal lure for detecting presence of E. ferrugineus. In contrast, the probability of detecting E. ferrugineus with traps baited with racemic $\gamma$-decalactone was $5 \%$ in Allumiere and $21 \%$ in Monte Venere, showing that this lure is suboptimal for the detection of this species. The analysis on the survey effort allocation showed that it is sufficient to use ten BCWT baited with 7-methyloctyl (Z)-4-decenoate for four days to reliably assess the absence of the species (with $\mathrm{SE} \leq 0.05$ ). In order to assess the presence of E. ferrugineus, as the BCWT with racemic $\gamma$-decalactone catch mainly the females of this species, that are usually active in the second half of the sampling period (July), we suggest to use these traps for a sampling restricted to the month of July, to obtain the best result with the lowest effort.

As discussed by Svensson et al. (2012), when using an attractive lure in order to sample populations of threatened species, a special care must be taken. Despite the use of all the necessary precautions, such as frequent checking of traps, the use of leaves around the bottles to shade the containers and the positioning of moistened cotton inside the traps to maintain humidity, a significant proportion of captured E. ferrugineus $(20 \%)$ died in the traps. This phenomenon could be due to the high maximum temperatures in our study areas during the sampling period, that usually were about $27-30^{\circ} \mathrm{C}$ but sometimes reached more than $32^{\circ}$. In studies on Swedish populations, which 
experience lower temperatures, this negative effect has not been observed (GS personal observation). The death of a few individuals during the end of a single sampling season may not represent a threat for the long-term persistence of a population, because E. ferrugineus has a multiyear lasting larval stage (up to six years) (Tolasch et al. 2007). However, as a precautionary principle, we discourage a massive use of these traps for more than one year at the same site, especially in Mediterranean countries, to avoid negative impacts on E. ferrugineus populations.

\section{Dispersal distances and patterns}

Contrary to what was suggested for the less vagile $O$. eremita (Ranius and Hedin 2001; Ranius 2006; Chiari et al. $2013 \mathrm{~b}$ ), that could be threatened by the loss of genetic variation due to low dispersal capacity (Ranius 2000), most of E. ferrugineus males (77\% in Allumiere and $91 \%$ in Monte Venere) dispersed from the sites of first capture. As a higher dispersal capacity can promote gene flow among populations (Hartl and Clark 2007), and thus reduce inbreeding effects, our data on E. ferrugineus suggest that this species is probably less threatened by habitat isolation than $O$. eremita. The longest cumulative distance covered by male and female E. ferrugineus during this study was $1,507 \mathrm{~m}$ and $895 \mathrm{~m}$, respectively. For both sexes the negative exponential function predicted almost the same dispersal pattern with about $51 \%$ of individuals moving distances $>250 \mathrm{~m}$. Chiari et al. (2013b) found that a female $O$. eremita was able to travel a distance of $1,504 \mathrm{~m}$, and $33 \%$ of beetles moved distances $>250 \mathrm{~m}$. These results indicate that both sexes of E. ferrugineus are more prone to displacement than $O$. eremita. The greater attitude to displacement for E. ferrugineus could facilitate tracking of available prey during the emergency season, and at a larger temporal scale it could make the species capable to track the successional changes of tree suitability in the landscape from one generation to another.

The maximum dispersal distance $(1.5 \mathrm{~km})$ registered in this study for E. ferrugineus (a male) corresponds to that registered for a female of $O$. eremita (Chiari et al. 2013b) in a radiotelemetric study. These distances are similar to those registered for other large saproxylic beetles: Lucanus cervus, $2.0 \mathrm{~km}$ (Rink and Sinsch 2007) and Rosalia alpina, $1.6 \mathrm{~km}$ (Drag et al. 2011). Data on both the dispersal distances and home range, acquired with the mark-recapture method instead of radio telemetry can be influenced by the trapping grid-size and by the distance among traps. Moreover the sequence of capture events and an attractive lure can interrupt the continuity in the animal movements (Lira and Fernandez 2009). Therefore, it is possible that the distances actually covered by E. ferrugineus are longer than those recorded in this study.
The influence of temperature on beetle activity

The flight activity of E. ferrugineus was not correlated with the temperature during the study period. In contrast, a study in Sweden, with lower average temperatures, found a positive correlation between the temperature and the flight activity of both $E$. ferrugineus and O. eremita (Larsson and Svensson 2011). In our study areas, where the climate is drier and warmer more or less constantly during the summer, these beetles are continuously active. It seems that either in Italy (our study) or in Sweden (Larsson and Svensson 2011) E. ferrugineus is active when the mean daily maximum temperature is above $21^{\circ} \mathrm{C}$. Probably, this mean temperature value represents a threshold over which this beetle is more or less constantly active. We can suppose that in northern Europe the flight activity of both the target species is higher in warmer days than in colder days, predicting a positive correlation between activity and temperature, and that maximum temperature is never a limiting factor in northern countries. On the contrary, for Mediterranean countries, further investigations could find a second threshold above which the activity of these species is suspended.

\section{Conclusions}

The present study contributes important information on the dispersal ecology and adult phenology of $O$. eremita and $E$. ferrugineus populations in Italy and allows comparisons with studies on populations of these species performed in Sweden. Ecological traits expressed by populations over a species range are not constant but may differ due to variation in e.g. availability and size of suitable habitat patches. For conservation purposes, comparing traits such as dispersal capacity and habitat requirements among populations of a species is important to understand potential variation in e.g. vulnerability to habitat fragmentation. Due to this variation not only the management of populations should be adapted to the local conditions but also the sampling strategy used to monitor such populations. This study also highlights the potential problems when using a highly efficient odor lure to study rare and threatened insects. Therefore, to detect the presence of E. ferrugineus, thanks to the high efficacy of the lure, it is suggested to reduce the trapping effort (ten traps for three days) during the peak of activity (e.g., the two central weeks of July, in our study areas). Such optimal period could vary according to the climatic conditions for different European countries, i.e. later at higher latitudes and altitude.

Unfortunately, pheromones or kairomones are unknown for most of the saproxylic species of the Habitat Directive. In such cases other non-destructive methods should be 
used. Other attractive methods, such as freshly cut log piles, or passive methods, such as emergence traps, were efficiently used for the monitoring of Morimus asper and Limoniscus violaceus, respectively (Chiari et al. 2013c; Gouix and Brustel 2012). The advantage of these methods, as in the case of pheromone traps, is the low sampling effort required: few sampling days in an area were sufficient to obtain meaningful information on presence and abundance of the species. When possible, trap methods (active or passive) should be preferred over the ones that cause an alteration of the habitat.

In this study, traps baited with the pheromones of the two species, $O$. eremita and E. ferrugineus, allowed us to acquire information on presence, abundance, dispersal patterns and daily activity of E. ferrugineus, a rather unknown species of conservation interest. All these parameters resulted in higher values than expected. The simultaneous analysis of the $O$. eremita populations in the same study areas, with the use of traps baited with racemic $\gamma$-decalactone, led us to enlighten the disproportion in abundance of the two species which have always been considered a predator-prey system. In fact, in northern and western Europe, both species are abundant and coexist in many forest stands, being reported to inhabit the same tree hollows. On the contrary, in Mediterranean areas $E$. ferrugineus is much more abundant than $O$. eremita and may occur also when the latter is scarce or absent. This suggests that E. ferrugineus may have a greater number of potential prey species throughout its distributional range, and feeding on large size larvae of beetles that live inside tree hollows such as many species of saproxylic scarab and darkling beetles.

In the study areas the populations of $O$. eremita appeared to be reduced to a minimum number of individuals, surely insufficient for sustaining the predator in both forests, and suggests two hypothesis, not mutually exclusive: (1) E. ferrugineus exploits a wide spectrum of preys but still shows a strong attraction for the pheromone of $O$. eremita even though the latter cannot be anymore its major prey; (2) the high predation pressure on larvae of $O$. eremita in small areas, is one of the factor affecting negatively its population abundance.

At a local scale the traps baited with $\gamma$-decalactone allowed to assess for the first time the presence of $O$. eremita in both the study areas. This scarab species was considered an indicator of rich beetle fauna in tree hollows (Ranius 2002) and E. ferrugineus has been associated to its presence by several authors (Larsson and Svensson 2011; Tolasch et al. 2007; Schaffrath 2003b). O. eremita has populations more abundant in Sweden, and the probability to detect the species using baited-traps is considerably higher there in comparison with the present study (Andresson et al. 2014). Thus, it should still be considered as a good indicator of both community richness and hollow microhabitat suitability and availability in Northern Europe, in conjunction with E. ferrugineus. Nevertheless, in southern Europe, E. ferrugineus is much more easily detected than $O$. eremita by specific pheromone traps. For this reason, the former is more likely to be a better indicator of saproxylic beetle richness than the latter when pheromone traps are deployed. Furthermore, because E. ferrugineus is a predator of other saproxylic species its abundance is likely to be a good indicator of overall richness of saproxylic assemblages.

Acknowledgments We sincerely thank Lara Redolfi De Zan, Giovanni Luca Scardaci, Francesca Bellotti, Emanuela Maurizi, Chiara Totta, Filippo Bianchi, Giacomo Cavalieri D'Oro, Fabio Turchetti, Sergio Muratore for field assistance. We are grateful to the management authorities of the two SCI investigated, "Boschi mesofili di Allumiere" (Università Agraria di Allumiere) and "Monte Fogliano e Monte Venere" (Riserva Naturale Regionale Lago di Vico), for authorizations and facilities. We also thank Fredrik Andersson for providing the synthetic 7-methyloctyl (Z)-4-decenoate used in this work. The work of SC is supported by the VABAS project.

\section{References}

Alexander KNA (2008) Tree biology and saproxylic Coleoptera: issues of definitions and conservation language. Rev Écol (Terre Vie) 63:1-6

Amstrup SC, McDonald TL, Manly BFJ (2005) Handbook of capturerecapture analysis. Princeton University Press, Princeton

Andresson K, Bergman KO, Andersson F, Hedenström E, Jansson N, Burman J, Winde I, Larsson MC, Milberg P (2014) Highaccuracy sampling of the saproxylic diversity indicators at regional scales with pheromones: the case of Elater ferrugineus (Coleoptera. Biol Conserv, Elateridae). doi:10.1016/j.biocon. 2014.01.007

Anonymous (1992) Directive 92/43 of the Council of the European Community on the conservation of habitats and wild fauna and flora. European Community, Brussels

Anton S, Dufour MC, Gadenne C (2007) Plasticity of olfactoryguided behaviour and its neurobiological basis: lessons from moths and locusts. Entomol Exp Appl 123:1-11. doi:10.1111/j. 1570-7458.2007.00516.x

Arakaki N, Nagayama A, Kobayashi A, Tarora K, Kishita M, Sadoyama Y, Mougi N, Kijima K, Suzuki Y, Akino T, Yasui H, Fukaya M (2008) Estimation of abundance and dispersal distance of the sugarcane click beetle Melanotus sakishimensis Ohira (Coleoptera: Elateridae) on Kurima Island, Okinawa, by mark-recapture experiments. Appl Entomol Zool 43:409-419. doi:10.1303/aez.2008.409

Barbour JD, Millar JG, Rodstein J, Ray AM, Alston DG, Rejzek M, Dutcher JD, Hanks LM (2011) Synthetic 3, 5-dimethyldodecanoic acid serves as a general attractant for multiple species of prionus(Coleoptera: Cerambycidae). Ann Entomol Soc Am 104:588-593. doi:10.1603/AN10182

Blackshaw RP, Vernon RS (2006) Spatiotemporal stability of two beetle populations in non-farmed habitats in an agricultural landscape. J Appl Ecol 43:680-689. doi:10.1111/j.1365-2664. 2006.01167.x

Boyce MS (1992) Population viability analysis. Annu Rev Ecol Syst 23:481-497 
Brouwers NC, Newton AC (2009) Movement rates of woodland invertebrates: a systematic review of empirical evidence. Insect Conserv Diver 2:10-22. doi:10.1111/j.1752-4598.2008.00041.x

Burnham KP, Anderson DR (2002) Model selection and multimodel inference: a practical information-theoretic approach. Springer, Berlin

Butenandt A, Beckmann R, Stamm D, Hecker E (1959) Über den Sexual-Lockstoff des Seidenspinners Bombyx mori. Reindarstellung und Konstitution. Z. Naturforsch. 14b:283-284

Chapman JW, Birkett MA, Pickett JA, Woodcock CM, Wood PJ (2002) Chemical ecology and conservation of the stag beetle, Lucanus cervus. In: Hardie J, Tosh CR, Powell G A8-chemical communication: from hormones to semiochemicals. Abstracts/ Comparative Biochemistry and Physiology Part A. vol 132, p S63

Chiari S, Carpaneto GM, Zauli A, Marini L, Audisio P, Ranius T (2012) Habitat of an endangered saproxylic beetle, Osmoderma eremita, in Mediterranean woodlands. Écoscience 19:299-307. doi:10.2980/19-4-3505

Chiari S, Zauli A, Mazziotta A, Luiselli L, Audisio P, Carpaneto GM (2013a) Surveying an endangered saproxylic beetle, Osmoderma eremita, in Mediterranean woodlands: a comparison between different capture methods. J Insect Conserv 17:171-181. doi:10. 1007/s10841-012-9495-y

Chiari S, Carpaneto GM, Zauli A, Zirpoli G, Audisio P, Ranius T (2013b) Dispersal patterns of a saproxylic beetle, Osmoderma eremita, in Mediterranean woodlands. Insect Conserv Diver 6:309-318. doi:10.1111/j.1752-4598.2012.00215.x

Chiari S, Bardiani M, Zauli A, Hardersen S, Mason F, Spada L, Campanaro A (2013c) Monitoring of the saproxylic beetle Morimus asper (Sulzer, 1776) (Coleoptera: Cerambycidae) with freshly cut $\log$ piles. J Insect Conserv. doi:10.1007/s10841-0139606-4

Craig CC (1953) On the utilization of marked specimens in estimating population of living insects. Biometrika 40:170-176

Davies ZG, Tyler C, Stewart GB, Pullin AS (2008) Are current management recommendations for saproxylic invertebrates effective? A systematic review. Biodivers Conserv 17:209-234. doi:10.1007/s10531-007-9242-y

Drag L, Hauck D, Pokluda P, Zimmermann K, Cizek L (2011) Demography and dispersal ability of a threatened saproxylic beetle: a mark-recapture study of the Longicorn Rosalia (Rosalia alpina). PLoS ONE 6:e21345. doi:10.1371/journal.pone. 0021345

Gouix N, Brustel H (2012) Emergence trap, a new method to survey Limoniscus violaceus (Coleoptera: Elateridae) from hollow trees. Biodivers Conserv 21:421-436. doi:10.1007/s10531-011-0190-1

Grove SJ (2002) Saproxylic insect ecology and the sustainable management of forests. Annu Rev Ecol Syst 33:1-23. doi:10. 1146/annurev.ecolsys.33.010802.150507

Gullan PJ, Cranston PS (2010) The insects: an outline of entomology, 4th edition. Wiley-Blackwell, New York

Hartl DL, Clark AG (2007) Principles of population genetics, 4th edn. Sinauer Associates Inc. Publishers, Sunderland, MA

Harvey D, Hawes CJ, Gange AC, Finch P, Chesmore D, Farr I (2011) Development of non-invasive monitoring methods for larvae and adults of the stag beetle. Lucanus cervus Insect Conserv Diver 4:4-14. doi:10.1111/j.1752-4598.2009.00072.x

Hedin J, Ranius T, Nilsson SJ, Smith HG (2008) Restricted dispersal in a flying beetle assessed by telemetry. Biodiv Conserv 17(3):675-684. doi:10.1007/s10531-007-9299-7

Hines JE, MacKenzie DI (2004) PRESENCE, vers. 4.0. http://www. mbr-pwrc.usgs.gov/software.html

Iablokoff AK (1943) Ethologie de quelques élaterides du massif de Fontainebleau. Mem Mus Natl Hist Nat (France) 18:83-160
Larsson MC, Svensson GP (2009) Pheromone monitoring of rare and threatened insects: exploiting a pheromone-kairomone system to estimate prey and predator abundance. Conserv Biol 23:1516-1525. doi:10.1111/j.1523-1739.2009.01263.x

Larsson MC, Svensson GP (2011) Monitoring spatiotemporal variation in abundance and dispersal by a pheromone-kairomone system in the threatened saproxylic beetles Osmoderma eremita and Elater ferrugineus. J Insect Conserv 15:891-902. doi:10. 1007/s10841-011-9388-5

Larsson MC, Hedin J, Svensson GP, Tolasch T, Francke W (2003) Characteristic odor of Osmoderma eremita identified as malereleased pheromone. J Chem Ecol 29:575-587

Lira PK, Fernandez FA (2009) A comparison of trapping- and radiotelemetry-based estimates of home range of the neotropical opossum Philander frenatus. Mamm Biol 74:1-8. doi:10.1016/j. mambio.2008.05.002

López-Pantoja G, Nevado LD, Sánches-Osorio I (2008) Markrecapture estimates of survival and recapture rates of Cerambyx welensii Küster (Coleoptera cerambycidae) in a cork oak dehesa in Huelva (Spain). Cent Eur J Biol 3:431-441. doi:10.2478/ s11535-008-0044-3

López-Pantoja G, Dominguez L, Sánches-Osorio I (2011) Analysis of Prinobius myardi Mulsant population dynamics in a Mediterranean cork oak stand. Ann soc entomol Fr 47:260-268. doi:10. 1080/00379271.2011.10697717

MacKenzie I, Royle JA (2005) Designing occupancy studies: general advice and allocating survey effort. J Appl Ecol 42:1105-1114. doi:10.1111/j.1365-2664.2005.01098.x

Magri D (1998) Quaternary history of Fagus in the Italian peninsula. Annali Botanica 56:147-154

Magri D (2008) Patterns of post-glacial spread and the extent of glacial refugia of European beech (Fagus sylvatica). J Biogeogr 35:450-463. doi:10.1111/j.1365-2699.2007.01803.x

Millar JG, McElfresh JS, Romero C, Vila M, Marí-Mena N, LopezVaamonde C (2010) Identification of the sex pheromone of a protected species, the Spanish Moon Moth Graellsia isabellae. J Chem Ecol 36:923-932. doi:10.1007/s10886-010-9831-1

Morbey YE, Ydenberg RC (2001) Protandrous arrival timing to breeding areas: a review. Ecol Lett 4:663-673. doi:10.1046/j. 1461-0248.2001.00265.x

Musa N, Andersson K, Burman J, Andersson F, Hedenström E, Jansson N, Paltto H, Westerberg L, Winde I, Larsson MC, Bergman K, Milberg P (2013) Using sex pheromone and a multiscale approach to predict the distribution of a rare Saproxylic Beetle. PLoS ONE 8:e66149. doi:10.1371/journal.pone.0066149

Nichols JD, Bailey LL, O'Connell AF Jr, Talancy NW, Grant EHC, Gilbert AT, Annand EM, Husband TP, Hines JE (2008) Multiscale occupancy estimation and modeling using multiple detection methods. J App Ecol 45:1321-1329. doi:10.1111/j.13652664.2008.01509.x

Nieto A, Alexander KNA (2010) European Red List of Saproxylic Beetles. Publications Office of the European Union, Luxembourg

Piovesan G, Alessandrini A, Biondi F, Di Filippo A, Schirone B, Ziaco E (2011) Bioclimatology, growth processes, longevity and structural attributes in Italian network of old-growth beech forests spreading from the Alps to the Appennines. Knapp HD, Fichtner A (eds) Beech forests natural heritage of Europe. Workshop at the International Academy for Nature Conservation. Isle of Vilm, Germany, 19-22 October 2010

Platia G (1994) Fauna d'Italia. Coleoptera Elateridae. Ed. Calderini, Bologna

Ranius T (2000) Minimum viable metapopulation size of a beetle, Osmoderma eremita, living in tree hollows. Anim Conserv 3:37-43. doi:10.1111/j.1469-1795.2000.tb00085.x 
Ranius T (2001) Constancy and asynchrony of Osmoderma eremita populations in tree hollows. Oecologia 126:208-215. doi:10. $1007 / \mathrm{s} 004420000515$

Ranius T (2002) Osmoderma eremita as an indicator of species richness of beetles in tree hollows. Biodiv Conserv 11:931-941. doi:10.1023/A:1015364020043

Ranius T (2006) Measuring the dispersal of saproxylic insects: a key characteristic for their conservation. Popul Ecol 48:177-188. doi:10.1007/s10144-006-0262-3

Ranius T, Hedin J (2001) The dispersal rate of a beetle, Osmoderma eremita, living in tree hollows. Oecologia 126:363-370. doi:10. $1007 / \mathrm{s} 004420000529$

Ranius T, Nilsson SG (1997) Habitat of Osmoderma eremita Scop. (Coleoptera: Scarabaeidae), a beetle living in hollow trees. J Insect Conserv 1:193-204. doi:10.1023/A:101841 6000766

Rink M, Sinsch U (2007) Radio-telemetric monitoring of dispersing stag beetles: implications for conservation. J Zool 272:235-243. doi:10.1111/j.1469-7998.2006.00282.x

Schaffrath U (2003b) Zu Lebensweise, Verbreitung und Gefährdung von Osmoderma eremita (Scopoli, 1763) (Coleoptera; Scarabaeoidea, Cetoniidae, Trichiinae) [Biology, distribution and threat of Osmoderma eremita (Scopoli, 1763) (Coleoptera; Scarabaeoidea, Cetoniidae, Trichiinae)]. Teil 2-Philippia 10:249-336 (in German)

Schallhart N, Wallinger C, Juen A, Traugott M (2009) Dispersal abilities of adult click beetles in arable land revealed by analysis of carbon stable isotopes. Agr For Entomol 11:333-339. doi:10. 1111/j.1461-9563.2009.00428.x

Speight MCD (1989) Sasproxylic invertebrates and their conservation. Nature and Environment Series 46, Council of Europe, Strasbourg

Stockland JN, Siitonen J, Jonsson BG (2012) Biodiversity in dead wood. Cambridge University Press, Cambridge. doi:10.1017/ CBO9781139025843

Svensson GP, Larsson MC (2008) Enantiomeric specificity in a pheromone-kairomone system of two threatened saproxylic beetles, Osmoderma eremita and Elater ferrugineus. J Chem Ecol 34:189-197. doi:10.1007/s10886-007-9423-x

Svensson GP, Larsson MC, Hedin J (2003) Air sampling of its pheromone to monitor the occurrence of Osmoderma eremita, a threatened beetle inhabiting hollow trees. J Insect Conserv 7:189-198. doi:10.1023/B:JICO.0000020896.71333.f6

Svensson GP, Larsson MC, Hedin J (2004) Attraction of the larval predator Elater ferrugineus to the sex pheromone of its prey, Osmoderma eremita, and its implication for conservation biology. J Chem Ecol 30:353-363. doi:10.1023/B:JOEC. $0000017982.51642 .8 \mathrm{c}$

Svensson G, Oleksa A, Gawroński R, Lassance JM, Larsson MC (2009) Enantiomeric conservation of the male-produced sex pheromone facilitates monitoring of threatened European hermit beetles (Osmoderma spp). Entomol Exp Appl 133(3):276-282. doi:10.1111/j.1570-7458.2009.00923.x

Svensson GP, Sahlin U, Brage B, Larsson MC (2011) Should I stay or should I go? Modelling dispersal strategies in saproxylic insects based on pheromone capture and radio telemetry: a case study on the threatened hermit beetle Osmoderma eremita. Biodivers Conserv 20:2883-2902. doi:10.1007/s10531-011-0150-9

Svensson GP, Liedtke C, Hedenström E, Breistein P, Bång J, Larsson MC (2012) Chemical ecology and insect conservation: optimising pheromone-based monitoring of the threatened saproxylic click beetle Elater ferrugineus. J Insect Conserv 16:549-555. doi:10.1007/s10841-011-9440-5

Thomas SL, Wagner RG, Halteman WA (2009) Influence of harvest gaps and coarse woody material on click beetles (Coleoptera: Elateridae) in Maine's Acadian forest. Biodivers Conserv 18:2405-2419. doi:10.1007/s10531-009-9597-3

Tolasch T, Fragstein M, Steidle JLM (2007) Sex pheromone of Elater ferrugineus L. (Coleoptera: Elateridae). J Chem Ecol 33:2156-2166. doi:10.1007/s10886-007-9365-3

Torres-Vila LM, Sanchez-González Á, Ponce-Escudero F, MartínVertedor D, Ferrero-García JJ (2012) Assessing mass trapping efficiency and population density of Cerambyx welensii Küster by mark-recapture in dehesa open woodlands. Eur J For Res. doi:10.1007/s10342-011-0579-0

Ufficio Idrografico (2013) Allumiere termo-pluvio database. http:// www.idrografico.roma.it/annali/. Accessed 12 Dec 2013

Witzgall P, Kirsch P, Cork A (2010) Sex pheromones and their impact on pest management. J Chem Ecol 36:80-100. doi:10. 1007/s10886-009-9737-y

Wunderground (2013) Historical whether database, Caprarola, meteo station ILAZIOCA3. http://www.wunderground.com/history/. Accessed 12 Dec 2013

Yamamura K, Kishita M, Arakari N, Kawamura F, Sadoyama Y (2003) Estimation of dispersal distance by mark-recapture experiments using traps: correction of bias caused by the artificial removal by traps. Popul Ecol 45:149-155

Ziaco E, Di Filippo A, Alessandrini A, Baliva M, D’Andrea E, Piovesan G (2012) Old-growth attributes in a network of Appennines (Italy) beech forests: disentangling the role of past human interferences and biogeoclimate. Plant Biosyst 146:153-166. doi:10.1080/11263504.2011.650729 